\title{
Virus e batteri nelle acque sotterranee
}

\section{Francesco La Vigna}

ROMA CAPITALE Dip.10 Tutela ambientale e del verde - Protezione Civile

Uff. Geologia ed Idrogeologia Ambientale - Roma

francesco.lavigna@comune.roma.it

L'incremento della popolazione e la sempre maggiore richiesta di acqua rendono necessario un approccio critico alla gestione delle risorse di acque sotterranee. Ciò deve essere particolarmente sentito per quei territori nei quali la risorsa idrica principale è rappresentata dalle acque sotterranee. È il caso, ad esempio, del nostro paese nel quale l'acqua utilizzata dalla popolazione è per circa l' $80 \%$ proveniente da corpi idrici sotterranei (Aulicino e Volerra, 2004).

La diffusa opinione che le acque sotterranee siano generalmente di buona qualità, considerata la naturale azione filtro del terreno nei confronti di contaminanti provenienti dagli strati superiori della superficie terrestre, risulta purtroppo ormai superata a causa della miriade di casi in cui le attività antropiche e/o gli eventi naturali hanno causato episodi più o meno importanti di contaminazione degli acquiferi. In genere però, quando si parla di contaminazione delle acque di falda ci si riferisce per la maggior parte a contaminazioni derivanti da sversamenti di idrocarburi, solventi clorurati, sostanze chimiche varie derivanti dalle attività antropiche e industriali. E' senza dubbio evidente che quelli appena citati siano i casi più frequenti, più numerosi e quindi più studiati, ma esiste la possibilità che le acque di falda siano contaminate anche da microrganismi.

Normalmente gli acquiferi sono abitati prevalentemente da comunità naturali (biocenosi) formate da microorganismi (protozoi, batteri e virus) nonché varie specie animali appartenenti alla microfauna. Poichè però nel terreno non c'è luce e le sostanze nutritive sono scarse, i microorganismi che vi abitano devono avere un alto grado di specializzazione.

Se non sono protette in misura sufficiente, le acque sotterranee possono quindi costituire un ambiente in cui anche eventuali "indesiderati” microrganismi patogeni, liberati in superficie, possono sopravvivere sotto certe condizioni e costituire gli agenti contaminanti. Questo può accadere, ad esempio, quando acque reflue biologiche e liquami vengono dispersi nei corpi d'acqua superficiali e nell'ambiente e di lì, a causa di condizioni idrogeologiche favorevoli migrano verso le acque sotterranee. I processi di depurazione delle acque infatti non possono eliminare completamente virus e batteri (Gabrieli et al. 2009) e spesso gli impianti di collettamento delle acque reflue domestiche non ricevono la giusta manutenzione determinando seri problemi di contaminazione diretta delle falde acquifere (Cronin et al., 2006).

Del resto a livello globale più di 2,2 milioni di persone, prevalentemente nei paesi in via di sviluppo, muoiono ogni anno per malattie provocate dalla scarsa qualità dell'acqua e i virus o batteri da essa trasportati (Park et al., 2010).

Recentemente, a causa di note epidemie virali che hanno decimato milioni di capi di allevamento in Asia, molte delle carcasse di questi animali sono state sepolte nel terreno senza gli opportuni presidi igienico-sanitari. Questi depositi di carcasse, dilavati dalle precipitazioni, hanno permesso agli agenti infettanti di migrare nelle falde acquifere e quindi di infettare nuovi allevamenti abbeverati dalle acque di falda, e in alcuni casi anche gli esseri umani (Kim e Kim, 2012).

I primi studi sulla microbiologia del secolo scorso indicavano che i microrganismi diminuivano con l'aumentare della profondità ed era opinione comune che i microrganismi fossero praticamente assenti negli acquiferi. La presenza di virus e batteri invece è stata riscontrata in studi recenti anche in grande profondità. In acquiferi svedesi sono stati ad esempio riscontrati virus sino a profondità di anche $450 \mathrm{~m}$ (Fig.1) (Kyle et al., 2008).

Ci sono diversi fattori che regolano la sopravvivenza e la migrazione dei virus dal momento che vengono introdotti in un acquifero. In generale il clima (ad esempio le temperature e le precipitazioni), la natura dei terreni (ad esempio il contenuto di argilla e la capacità di trattenere l'umidità) e ovviamente il tipo di virus o di microrganismo, sono i principali elementi che determinano il tempo di sopravvivenza di questi microorganismi e quindi di residenza nell'acquifero.

Alcuni studi hanno dimostrato come la temperatura, il $\mathrm{pH}$ e il contenuto di calcio delle acque siano per alcuni virus (MS2, Poliovirus1, Echovirus1) altamente correlati con il loro tempo di decadimento (Gerba, 1999; Yates et al., 1985). I batteri sono organismi microscopici (1-6 $\mu \mathrm{m})$ monocellulari con un nucleo; i virus sono agenti biologici submicroscopici (20-122 $\mathrm{nm}$ ) caratterizzati da acidi nucleici e una membrana proteica. I virus possono infettare non solo un animale a sangue caldo ma anche i batteri stessi; in questo modo può capitare che un virus persista in un ambiente a lui ostico all'interno di cellule batteriche ospiti (Nevecherya et al. 2005).

Negli studi relativi ad acque contaminate da microorganismi è dunque essenziale determinare quanto ognuno di essi possa sopravvivere sulla base delle caratteristiche in sito e quale sia la sua mobilità sulla base delle caratteristiche idrauliche degli acquiferi coinvolti.

Questo tipo di contaminazione delle acque sotterranee è particolarmente preoccupante quando interessa acquiferi non porosi, come substrati rocciosi ignei o metamorfici o carbonatici carsici. In questi acquiferi infatti il flusso delle acque sotterranee è veloce e diretto, con poca possibilità di inattività e quindi difficile permanenza all'interno della matrice. Lo stesso avviene per acquiferi porosi ma molto permeabili come corpi morenici, ghiaie fluviali e conglomerati (Bergher, 2008). Lalta velocità delle falde contenute in questi corpi acquiferi e 
i bassi tempi di residenza, possono permettere che in caso di contaminazione virale-batteriologica il tempo che intercorre dalla fonte al bersaglio sia breve a tal punto che i microorganismi riescono a sopravvivere pur non trovandosi nelle loro condizioni ideali.

Relativamente ai meccanismi di trasporto, la diffusione dei virus nelle acque sotterranee segue l'avvezione e la dispersione.

Ma quali sono le metodologie per bonificare le acque contaminate da questo tipo di inquinanti?

Le metodologie che sono riportate in letteratura prevedono o la semplice depurazione delle acque, una volta emunte, con trattamenti disinfettanti (inactivation) come la clorazione, o la filtrazione (removal) come quella che prevede la rimozione dei virus attraverso un "soil passage" quindi utilizzando le proprietà filtranti dei terreni stessi (Schijven, 2001; Schijven e Hassanizadeh, 2002).

I trattamenti disinfettanti possono essere eseguiti anche direttamente sull'acquifero (Durand, 2011) per mezzo di iniezioni di disinfettanti opportunamente selezionati e alla giusta concentrazione, in modo che l'effetto diluente delle acque sotterranee non limiti l'azione di inactivation sull'area di maggiore attività degli agenti patogeni.

La legislazione italiana vede nel D.Lgs. 2/2/2001, n.31 la norma che sancisce gli standard qualitativi delle acque destinate al consumo umano, dettando anche dei riferimenti circa $i$ limiti di concentrazione di alcuni agenti patogeni nelle acque captate, mentre il D.Lgs. 152/2006, testo unico ambientale, nel suo Titolo V della parte 4, relativamente alla bonifica dei siti contaminati, non disciplina questo tipo di contaminazione.

Acque sotterranee contaminate da microrganismi patogeni possono essere causa di affezioni di tipo epidemico nella popolazione. Nonostante l'importanza della conoscenza della diffusione di malattie di origine idrica usualmente descritte come epidemie, nel nostro territorio e in Europa i dati al riguardo sono scarsi poiché non vi è un organizzato sistema di sorveglianza per la rilevazione di malattie di origine idrica nella popolazione e le indagini (incluse le analisi delle acque) per accertarne le cause. Purtroppo anche in paesi industrializzati mancano le risorse sia di personale che economiche che supportino questo tipo di indagini (Aulicino e Volterra, 2004).

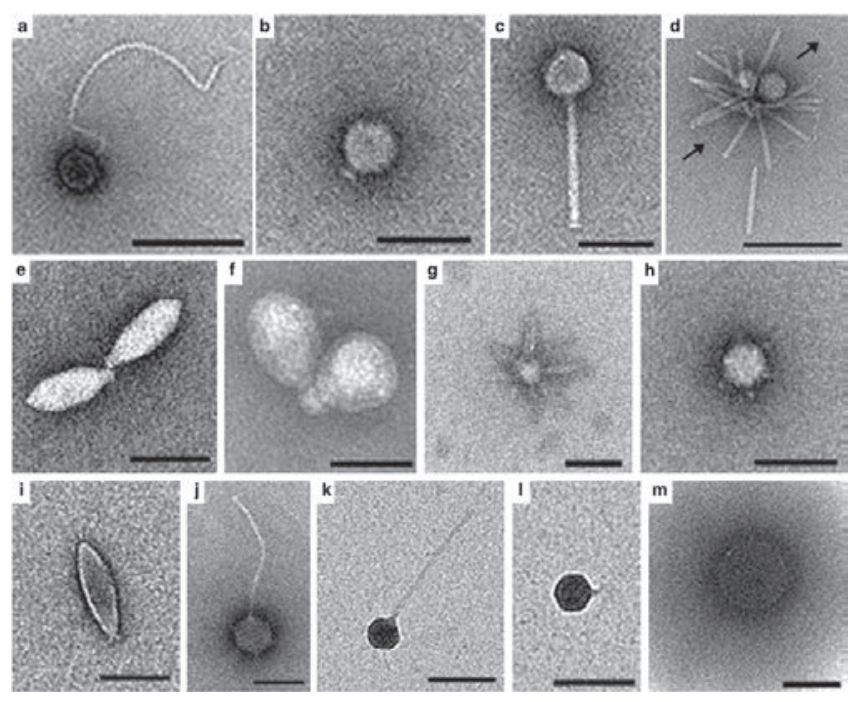

Fig.1: Alcuni virus riscontrati nelle acque sotterranee da Kyle et al. (2008) (a) Siphoviridae (B1); (b) polyhedral virus; (c) Myoviridae (A1); (d) Inoviridae; (e) Salterprovirus; (f) Guttaviridae; (g) polyhedral virus; (h) polyhedral virus (STIV-like); (i) Fuselloviridae; (j) Siphoviridae (B1); (k) Siphoviridae (B1); (1) Podoviridae (C1) e (m) polyhedral virus.

\section{BIBLIOGRAFIA}

Aulicino FA, Volterra L (2004). Microbiologia delle acque di diversa derivazione, Rapporti ISTISAN 04/14, Istituto Superiore di Sanità

Bergher P (2008). Viruses in ground water. In Hlavinek P et al (eds), Dangerous Pollutans (Xenobiotics) in Urban Water Cycle. Springer. 131-149

Cronin AA, Rueedi J, Joyce E, Pedley S (2006). Monitoring and managing the extent of microbiological pollution in urban groundwater systems in developed and developing countries. Urban Groundwater Management and Sustainability. NATO Science Series. 74: 299-314

Durand ML, Wietgrefe JM, Hart GK (2011). Managing the Challenges of Ground Water Rule. Compliance in South Florida. Florida water resources journal

Kyle1 JE, Eydal HSC, Ferris FG, Pedersen K (2008). Viruses in granitic groundwater from 69 to $450 \mathrm{~m}$ depth of the Äspö hard rock laboratory, Sweden. The ISME Journal. 2, doi:10.1038/ismej.2008.18

Kim HS, Kim K (2012). Microbial and chemical contamination of groundwater around livestock mortality burial sites in Korea - a review. Geosciences Journal. 16, Issue 4: 479-489

Gabrieli R, Maccari F, Ruta A, Panà A, Divizia M (2009). Norovirus Detection in Groundwater. Food and Environmental Virology. 2: $92-96$

Gerba CP (1999).Virus survival and transport in groundwater. Journal of Industrial Microbiology and Biotechnlogy. 22: 535-539

Yates MV, Gerba CP, Kelley LM (1985) Virus persistence in groundwater. Appl. Environ. Microbiol. 49 n.4: 778-781

Nevecherya IK, Shestakov VM, Mazaev VT, Shlepnina TG (2005). Survival rate of pathogenic bacteria and viruses in groundwater. Water Resources. 32, Issue 2: 209-214

Park SH, Kim EJ, Yun TH, Lee JH, Kim CK, Seo YH, Oh SA, Choi SS, Cho SJ, Kim MS, Han GY, Kim MY, Jeong HS, Cheon DS, Kim HS (2010). Human Enteric Viruses in Groundwater. Food and Environmental Virology. 2: 69-73

Schijven JF (2001). Virus removal from Groundwater by Soil Passage. Modeling, field and laboratory experiments. PhD Thesis, University of Delft.

Schijven JF, Hassanizadeh SM (2002). Virus removal by soil passage at field scale and groundwater protection of sandy aquifers. Water Science and Technology. 46 n3: 123-129 